\title{
Disruptions in feeding and body weight control in gastrin-releasing peptide receptor deficient mice
}

\author{
E E Ladenheim, L L Hampton", A C Whitney, W O White, \\ J F Battey ${ }^{1}$ and $\mathbf{T}$ H Moran \\ Department of Psychiatry and Behavioral Sciences, Johns Hopkins University School of Medicine, Baltimore, Maryland 21205, USA \\ ${ }^{1}$ Laboratory of Molecular Biology, National Institute on Deafness and Other Communication Disorders, National Institutes of Health, Rockville, \\ Maryland 20850, USA \\ (Requests for offprints should be addressed to E E Ladenheim; Email: laden@jhmi.edu)
}

\begin{abstract}
Bombesin $(\mathrm{BN})$ interacts with two mammalian receptor subtypes termed gastrin-releasing peptide (GRP)preferring (GRP-R) and neuromedin $\mathrm{B}$ (NMB)preferring (NMB-R) that may mediate the satiety action of $\mathrm{BN}$. We examined the feeding behavior of mice that were deficient in the GRP-R (GRP-R KO) to assess the overall contribution of this receptor subtype in the feeding actions of BN-related peptides. GRP-R KO mice failed to suppress glucose intake in response to systemically administered $\mathrm{BN}$ and $\mathrm{GRP}_{18-27}$, whereas both peptides elicited a potent reduction of intake in wild-type (WT) mice. Neither GRP-R KO nor WT mice suppressed glucose intake following NMB administration. Unlike the impaired responses to $\mathrm{BN}$-like peptides, the feeding inhibitory action of cholecystokinin was enhanced in
\end{abstract}

GRP-R KO mice. Consistent with behavioral results, GRP-R KO mice also exhibited a reduction in c-Fos immunoreactivity in the nucleus of the solitary tract (NTS) and paraventricular nucleus (PVN) following peripheral administration of $\mathrm{BN}$. An evaluation of meal patterns showed that GRP-R KO mice ate significantly more at each meal than WT mice, although total $24 \mathrm{~h}$ food consumption was equivalent. A long-term analysis of body weight revealed a significant elevation in GRP-R KO mice compared with WT littermates beginning at 45 weeks of age. These data suggest that the GRP-R mediates the feeding effects of BN-like peptides and participates in the termination of meals in mice.

Journal of Endocrinology (2002) 174, 273-281

\section{Introduction}

Bombesin, a tetradecapeptide originally isolated from amphibian skin (Anastasi et al. 1971), represents a large family of structurally related peptides with a wide array of physiological and behavioral effects in mammals (reviewed in Lebacq-Verheyden et al. 1990). Gastrin-releasing peptide (GRP) and neuromedin B (NMB) are two mammalian peptides that share close structural homology with $\mathrm{BN}$ and are widely distributed in the gastrointestinal tract and brain. To date, three mammalian $\mathrm{BN}$ receptor subtypes have been detected by molecular cloning techniques. These include the GRP-preferring receptor (GRP-R) (Spindel et al. 1990, Battey et al. 1991), NMB-preferring receptor (NMB-R) (Wada et al. 1991) and bombesin receptor subtype 3 (BRS-3) (Gorbulev et al. 1992, Fathi et al. 1993). Although BRS-3 shares approximately $50 \%$ of its amino acid sequence with GRP and NMB it does not interact with natural agonists that have high affinity for other BN-like peptide receptors and, at present, no endogenous ligand for BRS-3 has been identified (Mantey et al. 1997).
Exogenous administration of $\mathrm{BN}$, GRP and $\mathrm{NMB}$ suppresses food intake in a number of mammalian species, including humans (reviewed in Merali et al. 1999). BN binds with equal and high affinity to both NMB-R and GRP-R (von Schrenk et al. 1989) and activation of either or both receptor subtypes could produce feeding suppression. Studies in rats using selective agonists and antagonists to investigate the role of $\mathrm{BN}$ receptor subtypes in food intake have yielded conflicting results. For example, complete dose-response analyses comparing the feeding suppression produced by peripheral administration of $\mathrm{BN}$, GRP and NMB suggested the likelihood that BN's effects on food intake were mediated by both GRP and NMB receptors (Ladenheim et al. 1996b). However, experiments using highly selective antagonists for GRP-R have shown a complete blockade of $\mathrm{BN}$-induced satiety, supporting the view that only the GRP-R is involved in BN's feeding effects (Kirkham et al. 1994).

An alternative means of evaluating the role of a specific $\mathrm{BN}$ receptor subtype in feeding suppression by $\mathrm{BN}$-like peptides is through use of an animal model in which one of the receptor subtypes is deleted. The development of a 
mouse that is deficient in the GRP-R (Wada et al. 1997, Hampton et al. 1998) provides the opportunity to examine the relative contribution of GRP and NMB receptor subtypes to feeding suppression produced by BN-like peptides, as well as the role of this receptor subtype in normal feeding behavior.

In the present set of experiments we used this animal model to conduct a complete dose-response analysis for feeding suppression produced by peripheral administration of BN, GRP and NMB. We also compared central neuronal activation elicited by these peptides in GRP-R knockout (GRP-R KO) and wild-type (WT) mice using c-Fos immunohistochemistry. In addition, we examined suppression of food intake produced by cholecystokinin (CCK), a brain-gut peptide that potently reduces food intake but is not related to BN. To determine if deletion of GRP-R affects normal feeding and body weight in mice we performed a short-term analysis of meal patterns and long-term measurements of body weight. Verification of GRP-R deletion was evaluated by in vitro receptor autoradiography.

\section{Materials and Methods}

\section{Behavioral testing with peptides}

Adult male GRP-R KO mice and WT mice with a starting weight of 28-36 g were the experimental subjects. The generation of these mice is described in detail in a previous publication (Hampton et al. 1998). Mice were housed individually in plastic cages in a temperaturecontrolled room on a 12:12 h light dark cycle. Food and water were always available except during behavioral testing. All testing was done at $1400 \mathrm{~h}$ in individual $8 \mathrm{x} 8$ inch Plexiglas chambers during the light phase of the light dark cycle.

Mice were habituated to the experimental protocol prior to testing with peptides. Each mouse was removed from its home cage and injected i.p. with $0.9 \%$ saline. They were then placed in the Plexiglas test chamber with a $0.5 \mathrm{kcal} / \mathrm{ml}$ glucose solution freely available for $30 \mathrm{~min}$.

When consistent glucose intake was established (5 trials) mice were then tested for their feeding response to peptides. They were administered an i.p. injection of vehicle $(0 \cdot 9 \%$ bacteriostatic saline) or BN $(1,3 \cdot 2,10$ and $32 \mathrm{nmol} / \mathrm{kg}), \mathrm{GRP}_{18-27}(10,32,100$ and $320 \mathrm{nmol} / \mathrm{kg})$ and $\mathrm{NMB}(32,100$ and $320 \mathrm{nmol} / \mathrm{kg})$. In addition, the response to cholecystokinin (CCK), a non BN-related peptide that is known to reliably suppress food intake, was examined at doses of $0.32,1,3.2$ and $10 \mathrm{nmol} / \mathrm{kg}$. Immediately following the injection, mice were given access to $0.5 \mathrm{kcal} / \mathrm{ml}$ glucose and the volume consumed was recorded 15 and 30 min later. All peptides were given in a volume of $1 \mathrm{ml} / 100 \mathrm{~g}$ body weight. Doses of peptides were administered in a counter-balanced design in randomized order. Doses of peptide were administered at least
$48 \mathrm{~h}$ apart and preceded by a day in which saline was administered. All doses of one peptide were completed before testing the next peptide. The order for testing was BN, GRP, NMB and CCK.

Glucose intake after i.p. saline injection was averaged across test days to attain baseline intake for each peptide. Data for all peptides were analyzed separately for each group and at each time point using repeated measures ANOVA followed by planned $t$ comparisons. For CCK, between-group comparisons were also performed.

\section{Meal pattern analysis}

To evaluate normal feeding behavior in GRP-R KO and WT mice, an analysis of meal patterns was conducted. Mice ( $n=5$ per group) were placed in a feeding apparatus consisting of individual stations with a running wheel connected to a nest box constructed of black opaque Plexiglas $(15 \times 25 \times 15 \mathrm{~cm})$ and an opening for food access. The food bin was equipped with an infrared emitter and a detector that indicated when a $45 \mathrm{mg}$ pellet (Bioserv rodent grain-based diet) was in the feeder. Pellets were delivered via a pellet dispenser attached to the outside of the feeding apparatus. Tap water was available at all times. Feeding stations were housed in a temperaturecontrolled room on a 12:12 h light dark cycle.

Feeding stations were connected to a computer interface which recorded the number of pellets removed from the feeding bin at $5 \mathrm{~min}$ intervals using CONMAN (Contingency Management) software (Spyder Systems, Bloomington, IN, USA). Meal criteria were set for greater than one pellet, followed by $10 \mathrm{~min}$ with no feeding. Because we were only interested in food intake, the running wheel was in a locked position for this experiment.

Prior to data collection, GRP-R KO and WT mice were acclimated to the feeding apparatus for at least 4 days to assure that they reliably took pellets from the feeding bin and produced minimal spillage. Twenty-four hour measurements for total grams of food consumed, meal number, pellet number and meal size were collected. Data for each measurement were analyzed using Student's unpaired $t$-test (one-tailed).

\section{c-Fos immunohistochemistry}

Tissue was collected for the determination of brain c-Fos activation induced by i.p. injection of BN in GRP-R KO $(n=8,44 \cdot 7 \pm 3 \cdot 2 \mathrm{~g})$ and WT mice $(n=7,40 \pm 2 \cdot 3 \mathrm{~g})$. For this experiment, four GRP-R KO and two WT mice that had undergone the behavioral testing described above were used. Additional GRP-R KO mice $(n=4)$ and WT mice $(n=5)$ that were not involved in this experiment were added later to increase the number of animals for evaluation. Mice were deprived of food for $6 \mathrm{~h}$ before being injected i.p. with either saline or $32 \mathrm{nmol} / \mathrm{kg} \mathrm{BN}$. 
Seventy-five minutes later, mice were anesthetized with Euthasol (pentobarbital sodium and phenytoin, Delmarva Laboratories), and perfused transcardially with $25 \mathrm{ml}$ 0.1 M phosphate-buffered saline (PBS, $\mathrm{pH} 7 \cdot 4$ ) followed by $25 \mathrm{ml} \mathrm{4 \%}$ paraformaldehyde in PBS. The fixed brains were removed and cryoprotected in 25\% sucrose in PBS $(\mathrm{w} / \mathrm{v})$. Brains were cut on a cryostat at a thickness of $30 \mu \mathrm{m}$ and tissue sections were collected in PBS.

Prior to the immunohistochemical procedure, the sections were incubated in $0.3 \%$ hydrogen peroxide for $60 \mathrm{~min}$, thoroughly washed in PBS and pre-absorbed with normal goat serum in $0.1 \mathrm{M}$ PBS containing $0.1 \%$ Triton $\mathrm{X}-100$. They were then incubated for $48 \mathrm{~h}$ at $4{ }^{\circ} \mathrm{C}$ in rabbit anti-c-Fos antiserum (Oncogene Science, 1:30 000) followed by incubation in biotinylated goat anti-rabbit IgG and avidin-biotin-peroxidase complex (Elite Vectastain Kit, Vector Labs, Burlingame, CA, USA). The reaction product was visualized using nickel sulfate enhanced diaminobenzine (DAB) as the chromagen. Sections were mounted onto gelatin-coated slides, dehydrated in an ascending series of alcohols and coverslipped.

For quantification of c-Fos immunoreactivity, images from the area postrema (AP), nucleus of the solitary tract (NTS) and paraventricular nucleus of the hypothalamus (PVN) in WT and GRP-R KO mice were captured with a video camera attached to a light microscope. The areas of interest were outlined based on cellular morphology and c-Fos immunoreactive nuclei were counted using automated image analysis software. Counts were made at one level of the AP ( $-7.48 \mathrm{~mm}$ bregma), three levels of the medial NTS (obex, -7.48 and $-7.20 \mathrm{~mm}$ bregma) and in the PVN, as described in the atlas of Franklin \& Paxinos (1997). These brain regions were selected for evaluation because they exhibit increased c-Fos activation in response to i.p. injection of $\mathrm{BN}$ ( $\mathrm{Li} \&$ Rowland 1996) and participate in the control of food intake in rats.

c-Fos activation in response to i.p. injection of saline in a combined control group consisting of GRP-R KO $(n=3)$ and WT $(n=2)$ mice was compared with the response produced by $32 \mathrm{nmol} / \mathrm{kg}$ BN in GRP-R KO $(n=5)$ and WT $(n=5)$ mice using separate ANOVAs at each brain site.

\section{Body weight}

To determine if differences in body weight gain were present between WT and GRP-R KO mice, monthly body weights over a period of 25-54 months were obtained from animals backcrossed nine generations to C57BL $/ \mathrm{J} 6$ mice ( $n=7$ per group). Data were analyzed by ANOVA and analyses of simple effects were used to determine age-related differences between groups.

\section{Receptor autoradiography}

To verify that GRP-R deficient mice were devoid of functional GRP receptors, receptor autoradiography was performed on the fundal region of the stomach, an area that expresses high densities of GRP-R (Ladenheim et al. 1997). To determine if NMB receptors remained intact, receptor autoradiography was also performed on the anterior olfactory nucleus, a brain region containing a high density of NMB-R (Wada et al. 1991, Ladenheim et al. 1992).

At the conclusion of the behavioral experiments, GRP-R KO $(n=3)$ and WT mice $(n=3)$ were anesthetized with Euthasol (Delmarva Labs) and the gastric fundus was removed and flash frozen in isopentane that had been cooled on dry ice. Twenty micrometer tissue sections were cut on a cryostat, thaw-mounted onto gelatin-coated slides and stored at $-70{ }^{\circ} \mathrm{C}$ until used for analysis of GRP-R binding.

Tissue sections were preincubated for $20 \mathrm{~min}$ at room temperature in $50 \mathrm{mM}$ Mes buffer that contained $0.5 \%$ BSA ( $\mathrm{pH}$ 6.5). They were then incubated at room temperature in $50 \mathrm{mM}$ Mes buffer with the addition of $0 \cdot 5 \% \mathrm{BSA}, 130 \mathrm{mM} \mathrm{NaCl}, 7 \cdot 7 \mathrm{mM} \mathrm{KCl}, 5 \mathrm{mM} \mathrm{MgCl}$, $1 \mathrm{mM}$ EGTA, $0 \cdot 025 \%$ bacitracin, $4 \mathrm{mg} / \mathrm{ml}$ leupeptin, $2 \mathrm{mg} / \mathrm{ml}$ chymostatin and $40 \mathrm{pM}\left[{ }^{125} \mathrm{I}_{-} \mathrm{Tyr}^{4}\right] \mathrm{BN}$ for $300 \mathrm{~min}$. The sections were thoroughly washed $(4 \times 5 \mathrm{~min})$ in ice-cold $50 \mathrm{mM}$ Mes buffer containing $0.5 \%$ BSA and dried under a stream of warm air. They were then dessicated overnight and placed in an X-ray cassette with Hyperfilm-3H (Amersham) for 3 days.

\section{Results}

\section{Receptor autoradiography}

Binding of ${ }^{125} \mathrm{I}-\left[\mathrm{Tyr}^{4}\right] \mathrm{BN}$ in the gastric fundus is shown in Fig. $1 \mathrm{~A}$ and $\mathrm{B}$. There was a high density of binding exhibited in the circular muscle layer in WT mice (Fig. 1A). In contrast, binding of $\left[{ }^{125} \mathrm{I}_{-} \mathrm{Tyr}^{4}\right] \mathrm{BN}$ was absent in this region in GRP-R KO mice (Fig. 1B).

In the anterior olfactory nucleus, the density of $\mathrm{BN}$ binding sites was comparable in both WT (Fig. 1C) and GRP-R KO mice (Fig. 1D). Binding sites in this brain region have previously been characterized as NMB-R (Wada et al. 1990, 1991, Ladenheim et al. 1992) and thus should be unaffected. However, ${ }^{125} \mathrm{I}-\left[\mathrm{Tyr}^{4}\right] \mathrm{BN}$ binding in the cortex was reduced in GRP-R KO compared with WT mice because this region contains a mixture of GRP-Rs and NMB-Rs (Wada et al. 1990, Ladenheim et al. 1992) (Fig. 1D).

\section{Behavioral testing with peptides}

The effects of $\mathrm{BN}, \mathrm{GRP}_{18-27}, \mathrm{NMB}$ and $\mathrm{CCK}$ on suppression of glucose intake in GRP-R KO and WT mice are shown in Figs 2-5. After i.p. administration of BN (Fig. 2), WT mice significantly suppressed glucose intake at $15 \mathrm{~min}$ (Fig. $2 \mathrm{~A}, F(5,20)=7 \cdot 073, P<0 \cdot 001)$ and 

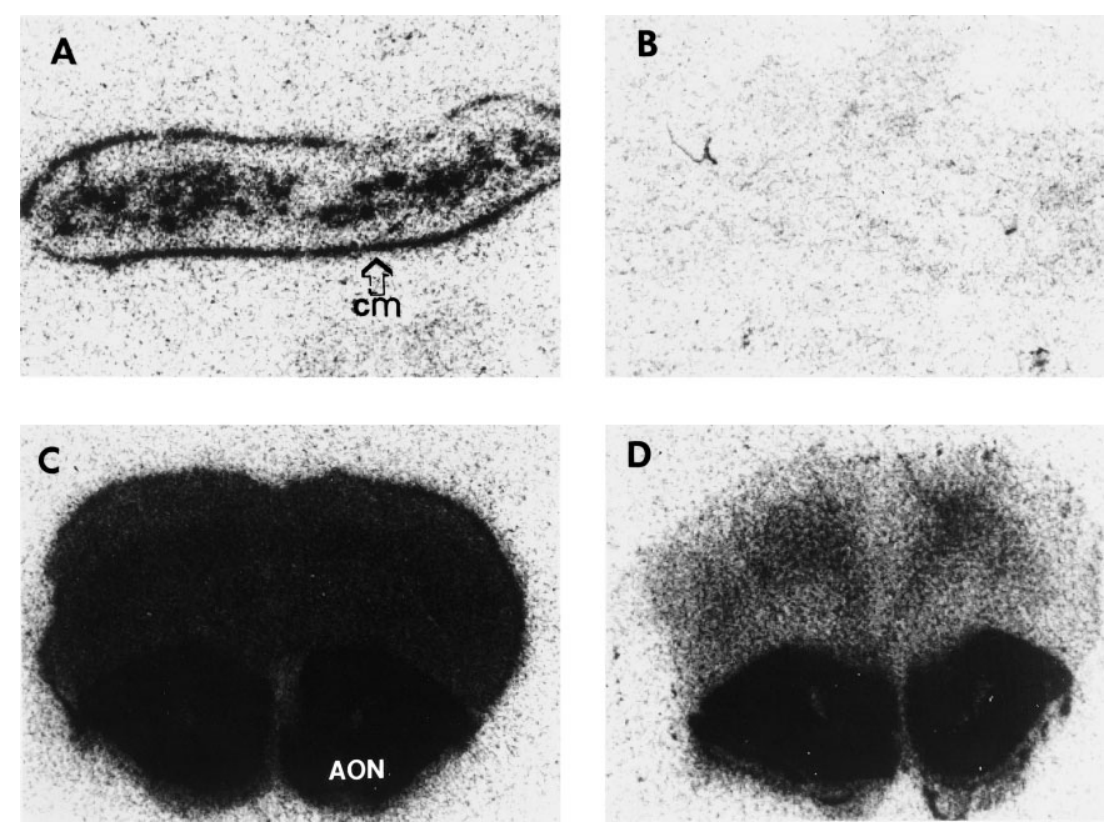

Figure 1 Photomicrographs of autoradiographs showing total binding of ${ }^{125} \mathrm{I}-\left[\mathrm{Tyr}^{4}\right] \mathrm{BN}$ in the gastric fundus of a WT mouse $(\mathrm{A})(\mathrm{cm}$, circular muscle) and a gastrin-releasing peptide-preferring receptor knockout (GRP-R KO) mouse (B). WT (C) and GRP-R KO mouse (D) brain at the level of the anterior olfactory nucleus (AON). The gastric fundus in GRP-R KO mice was devoid of ${ }^{125} \mathrm{I}-\left[\mathrm{Tyr}^{4}\right]$ bombesin (BN) binding because this region contains high densities of GRP-R. GRP-R KO mice exhibited no differences in binding in the $A O N$ because this region contains neuromedin B-preferring receptors (NMB-R). The cortex possesses a mixture of GRP-R and NMB-R therefore WT mice exhibit less binding in this region.

$30 \mathrm{~min}$ (Fig. 2B, $F(5,20)=4 \cdot 371, P=0 \cdot 011$ ). The comparison of individual doses revealed that $\mathrm{BN}$-induced suppression of glucose intake occurred with 10 and $32 \mathrm{nmol} / \mathrm{kg}$ at $15 \mathrm{~min}$ and with $3 \cdot 2,10$ and $32 \mathrm{nmol} / \mathrm{kg}$ at $30 \min (P<0 \cdot 05)$. In contrast, GRP-R KO mice failed to suppress glucose intake at any dose at either time point $(P>0 \cdot 05)$.

In response to i.p. administration of $\mathrm{GRP}_{18-27}$ (Fig. 3), WT mice exhibited a significant dose-dependent reduction of glucose intake at both $15 \mathrm{~min}$ (Fig. 3A, $F(5,20)=$ $4 \cdot 20, P=0 \cdot 01$ ) and $30 \mathrm{~min}$ (Fig. 3B, $F(5,20)=0.3287$, $P<0.03)$. The suppression of glucose intake was significant at the 32, 100 and $320 \mathrm{nmol} / \mathrm{kg}$ dosages at both 15 and $30 \mathrm{~min}$. As seen with BN, the GRP-R KO mice did not suppress glucose at any dose tested $(P>0 \cdot 05)$.

When NMB was injected i.p., neither WT or GRP-R $\mathrm{KO}$ mice reduced glucose intake at any dose tested at either $15 \mathrm{~min}$ (Fig. 4A) or $30 \mathrm{~min}$ (Fig. 4B) post-injection $(P>0 \cdot 05)$.

Administration of the non-BN-related peptide, CCK (Fig. 5), produced a significant dose effect at $15 \mathrm{~min}$ (Fig. 5A) in both GRP-R KO mice $(F(4,16)=19 \cdot 67$, $P<0 \cdot 0001)$ and WT mice $(F(5,20)=35 \cdot 1, P<0 \cdot 0001)$. Planned $t$ comparisons indicated that GRP-R KO mice significantly suppressed intake at the $1,3 \cdot 2$ and
$10 \mathrm{nmol} / \mathrm{kg}$ doses, whereas a significant suppression was not seen until the $3 \cdot 2 \mathrm{nmol} / \mathrm{kg}$ dose in WT mice.

At $30 \mathrm{~min}$ (Fig. 5B), a significant dose effect and a significant group-dose interaction were evident $(F(4,36)=3 \cdot 516, P=0 \cdot 016)$, indicating that the degree of suppression was greater in the GRP-R KO than WT mice at high doses of CCK.

\section{Meal pattern analysis}

Results from the $24 \mathrm{~h}$ analysis of feeding patterns in WT and GRP-R KO mice are shown in Table 1. The total amount of food consumed (total grams and total number of pellets) within this time period was not significantly different between groups $(P>0 \cdot 05)$. Meal size (number of pellets and grams consumed) was significantly greater in GRP-R KO mice compared with WT mice $(P<0 \cdot 05)$. While there was a trend towards a decreased number of meals consumed within $24 \mathrm{~h}$ this did not reach statistical significance.

\section{c-Fos immunohistochemistry}

Quantification of c-Fos immunoreactive cells following i.p. administration of saline or $32 \mathrm{nmol} / \mathrm{kg} \mathrm{BN}$ in WT and GRP-R KO mice is shown in Fig. 6. This dose of BN 
A

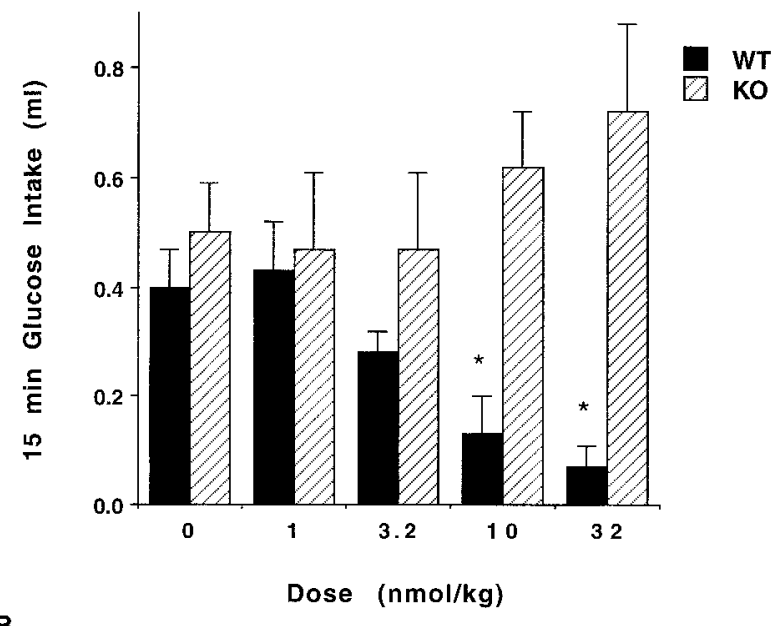

B

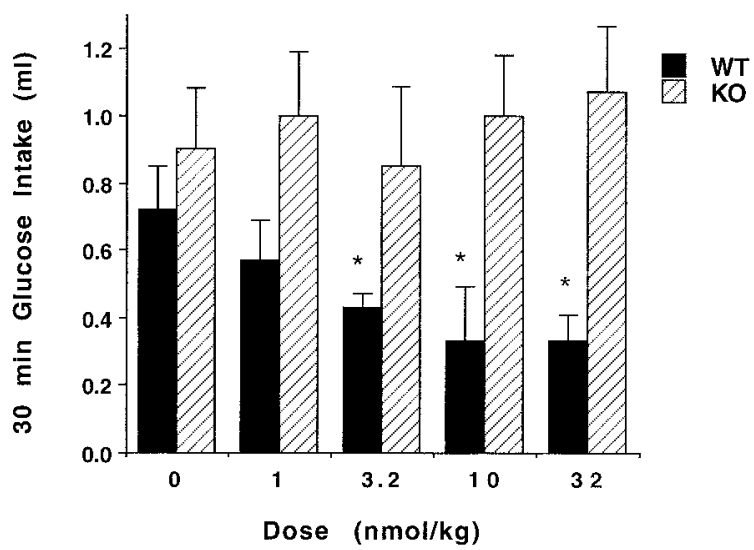

Figure 2 Effects of $0,1,3 \cdot 2,10$ and $32 \mathrm{nmol} / \mathrm{kg} \mathrm{BN}$ on glucose intake 15 (A) and 30 min (B) post-injection in WT and GRP-R KO mice. GRP-R KO mice failed to suppress glucose intake at any dose. Data are expressed as means \pm S.E. *Significantly different from baseline $(0)$ condition $(P<0 \cdot 05)$.

elicited a significant increase in c-Fos activation in WT mice in all brain regions evaluated $(P<0 \cdot 05)$. Significant elevations in $\mathrm{BN}$-induced c-Fos immunoreactivity in GRP-R KO mice were detected only in the PVN, however the degree of activation was significantly less compared with WT mice $(P<0 \cdot 05)$.

\section{Body weight}

The body weights of GRP-R KO and WT control mice over a period of 25-54 weeks are shown in Fig. 7. GRP-R $\mathrm{KO}$ body weights were significantly greater than WT beginning at week $45(P<0 \cdot 01)$.

\section{Discussion}

In an earlier study, we demonstrated that mice with a targeted deletion of the GRP-R exhibited several differ-
A
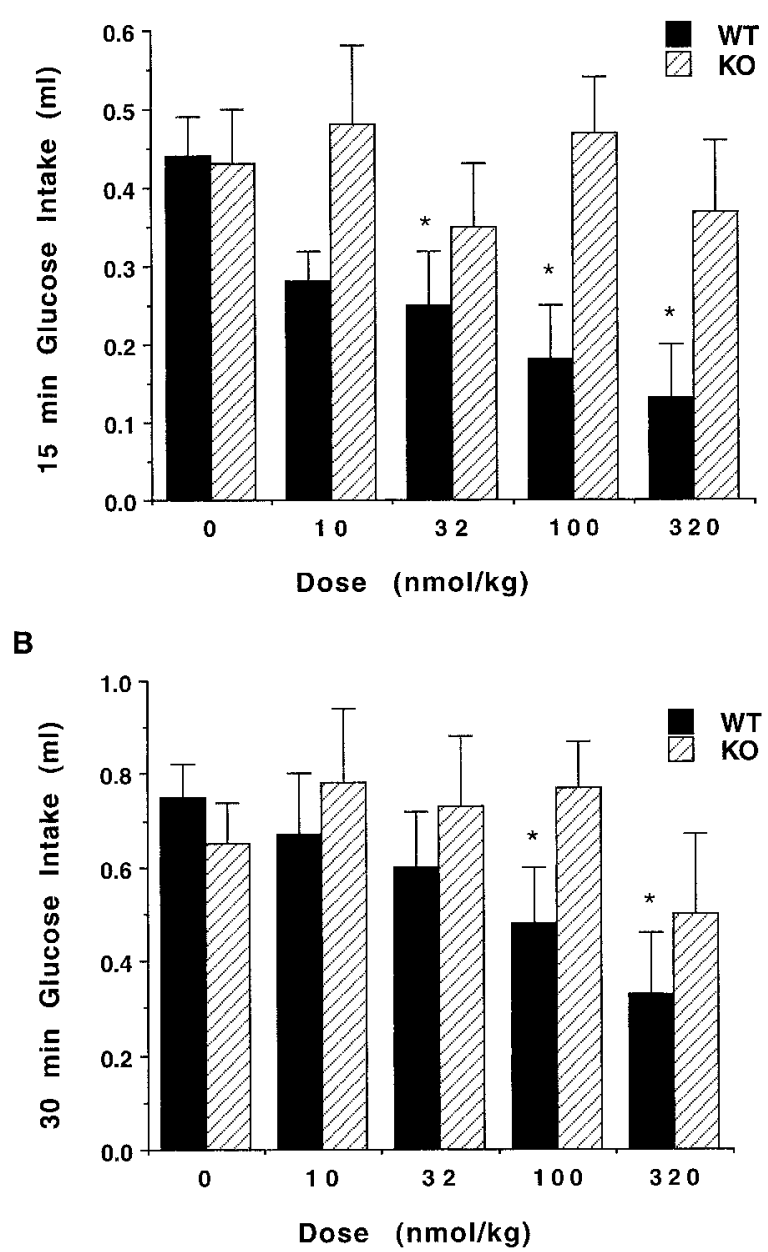

Figure 3 Effects of $0,10,32,100$ and $320 \mathrm{nmol} / \mathrm{kg} \mathrm{GRP}_{18-27}$ on glucose intake $15(\mathrm{~A})$ and $30 \mathrm{~min}(\mathrm{~B})$ post-injection in WT and GRP-R KO mice. GRP-R KO mice failed to suppress glucose intake at any dose. Data are expressed as means \pm S.E. ${ }^{*}$ Significantly different from baseline $(0)$ condition $(P<0 \cdot 05)$.

ences compared with their WT littermates. Although measures of embryonic mortality, reproductive abnormalities and organ pathology were similar to WT littermates, GRP-R KO mice displayed a lack of $\left[{ }^{125} \mathrm{I}-\mathrm{Tyr}^{4}\right] \mathrm{BN}$ binding to mouse acinar cells, a loss of $\mathrm{BN}$-induced amylase release from dispersed pancreatic acinar cells and a deficit $\mathrm{BN}$-induced suppression of food intake (Hampton et al. 1998).

Based on the binding characteristics of $\mathrm{BN}$, our initial interpretation from our previous study was that GRP-R was solely responsible for the feeding effects of $\mathrm{BN}$. However, because experiments examining the contribution of individual BN receptor subtypes to feeding suppression by $\mathrm{BN}$ in rats have often been difficult to reconcile it was also necessary to evaluate the feeding 
A

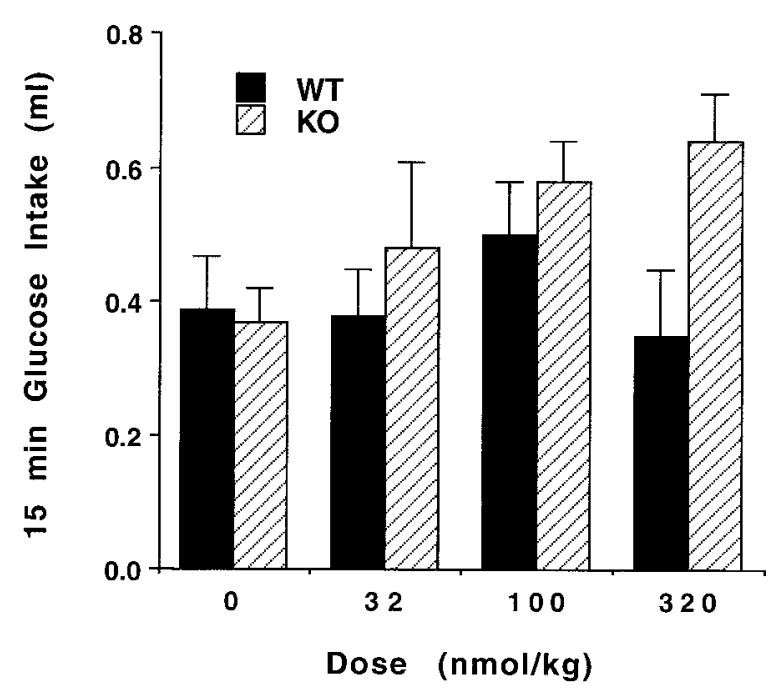

B

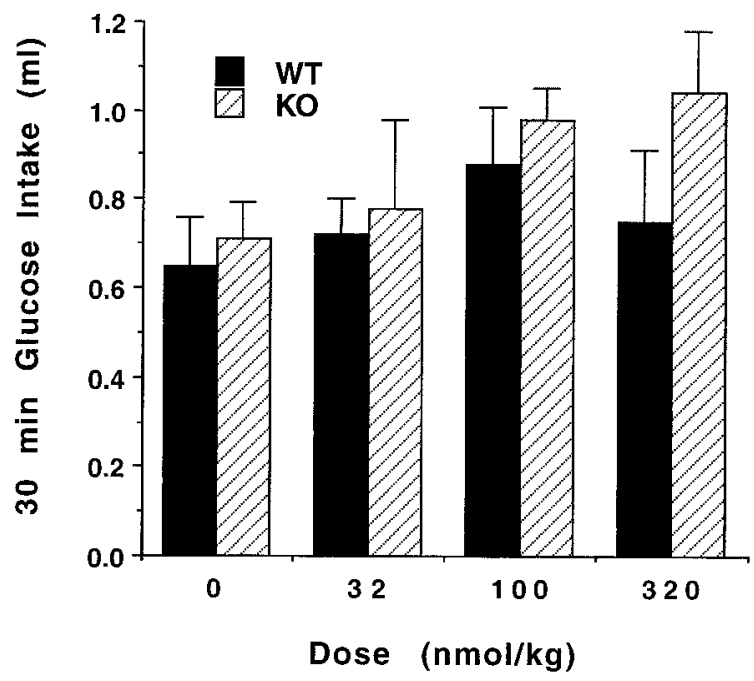

Figure 4 Effects of NMB on glucose intake $15(\mathrm{~A})$ and $30 \mathrm{~min}(\mathrm{~B})$ after post-injection in WT and GRP-R KO mice. NMB did not reduce glucose intake in either group $(P>0.05)$.

effects of GRP and NMB in GRP-R KO and WT mice to be completely confident in this interpretation.

Therefore, in the present study we fully characterized the feeding response to $\mathrm{BN}$-like peptides in GRP-R KO mice, as well as examined the contribution of GRP-R to body weight and normal controls of food intake. The finding that $\mathrm{BN}$ failed to reduce food intake in GRP-R KO mice replicates the results of our earlier study (Hampton et al. 1998). In the present study, the inability of GRP to suppress glucose intake in GRP-R KO mice and lack of effect of NMB in both GRP-R KO and WT
A

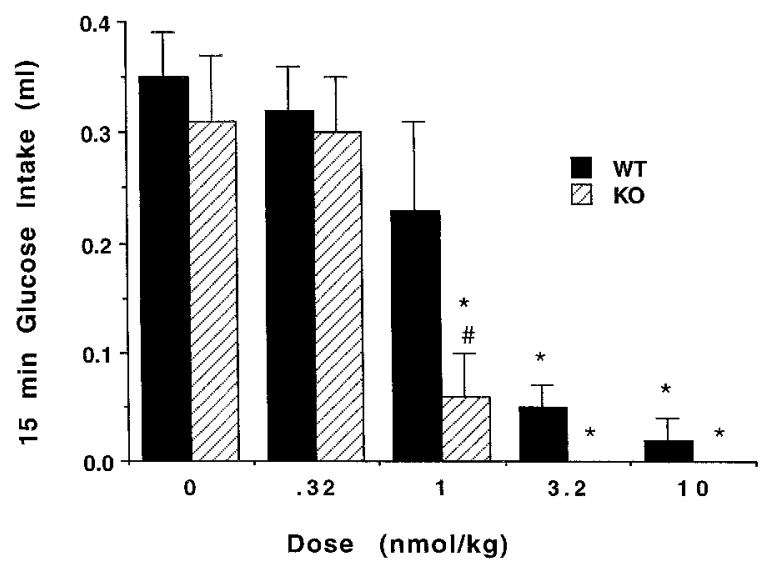

B

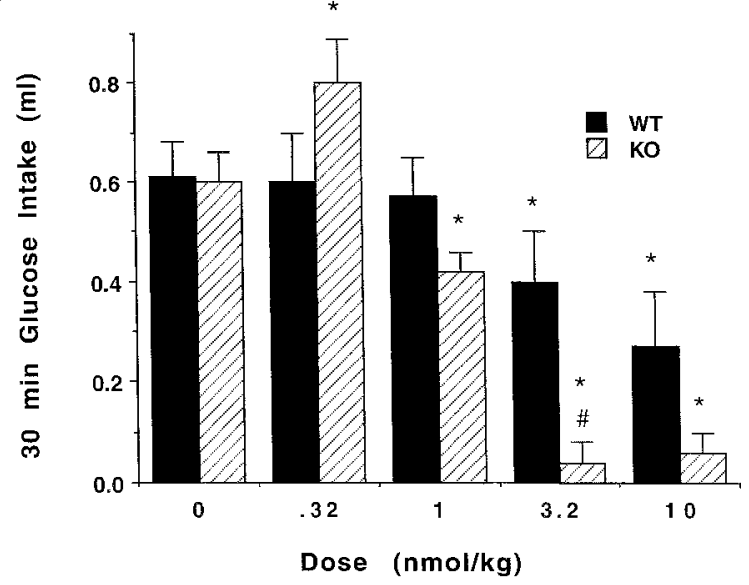

Figure 5 Effects of cholecystokinin (CCK) on glucose intake 15 (A) and $30 \mathrm{~min}(\mathrm{~B})$ after injection in WT and GRP-R KO mice. CCK produced a significant suppression of glucose in WT and KO mice. Both the sensitivity and magnitude of suppression were greater in $\mathrm{KO}$ than in WT mice. Data are expressed as means \pm S.E. ${ }^{*}$ Significantly different from baseline $(0 \mathrm{nmol} / \mathrm{kg})$ condition $(P<0 \cdot 05)$. ${ }^{\#}$ Significantly different from WT.

Table 1 Analysis of $24 \mathrm{~h}$ meal patterns in WT and GRP-R KO mice

\begin{tabular}{|c|c|c|}
\hline \multirow[b]{2}{*}{ Meal parameters } & WT $(n=5)$ & GRP-R KO $(n=5)$ \\
\hline & & \\
\hline Total $(g)$ & $5 \cdot 09 \pm 0 \cdot 15$ & $5 \cdot 22 \pm 0 \cdot 63$ \\
\hline No. pellets & $113 \cdot 4 \pm 3 \cdot 3$ & $116 \pm 12 \cdot 3$ \\
\hline No. meals & $36 \cdot 7 \pm 2 \cdot 5$ & $29 \cdot 6 \pm 5 \cdot 7$ \\
\hline Meal size (pellets) & $3 \cdot 13 \pm 0 \cdot 21$ & $4 \cdot 08 \pm 0 \cdot 48^{*}$ \\
\hline Meal size (g) & $0 \cdot 14 \pm 0 \cdot 01$ & $0 \cdot 18 \pm 0 \cdot 02^{*}$ \\
\hline
\end{tabular}

GRP-R KO mice consumed significantly more at each meal than WT mice, although $24 \mathrm{~h}$ intake was equivalent. *Significantly different from WT $(P<0 \cdot 05)$. 


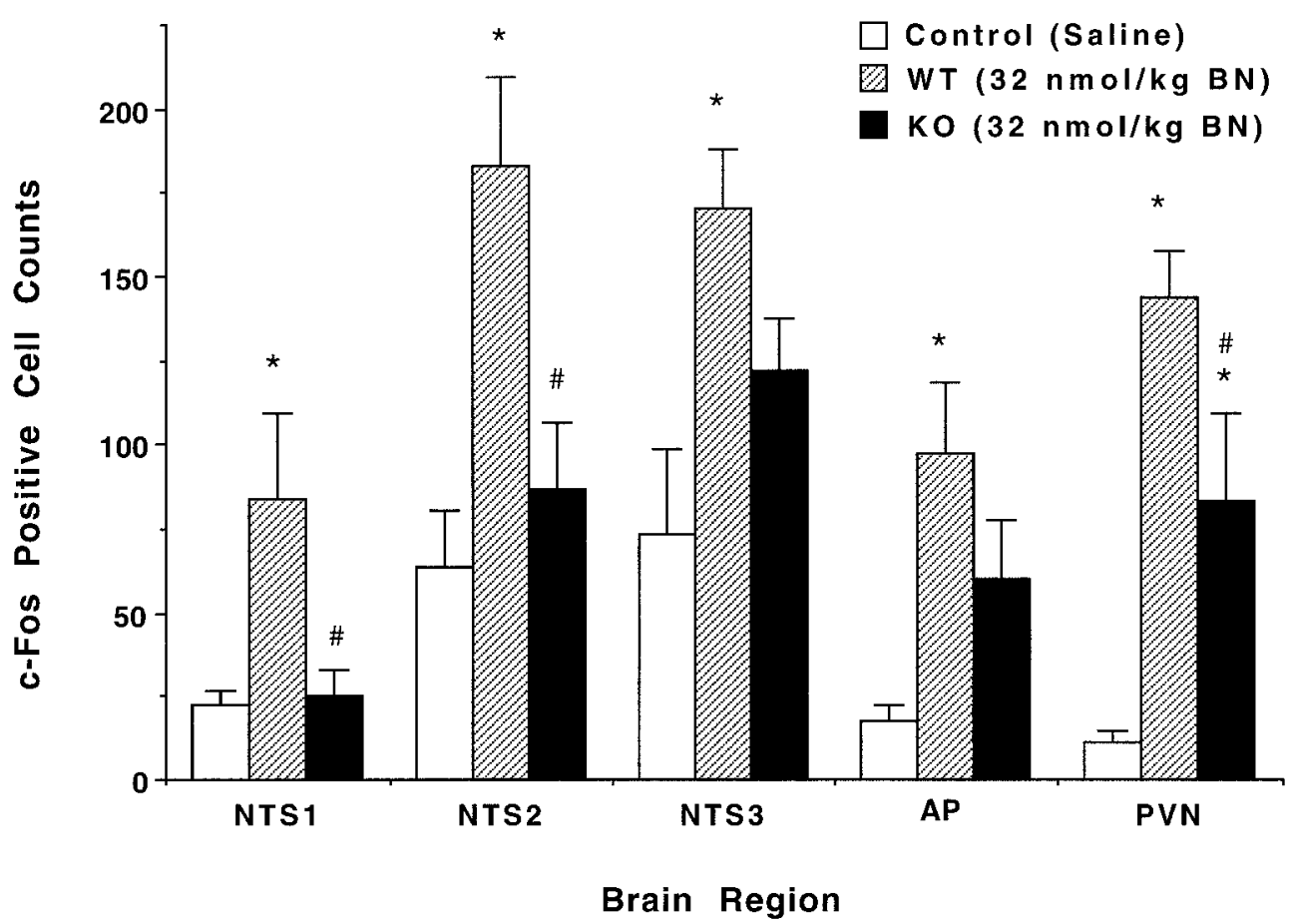

Figure 6 c-Fos positive cell counts (means \pm S.E.) in five brain regions in WT and GRP-R KO mice after treatment with either $0.9 \%$ saline (Control) or $32 \mathrm{nmol} / \mathrm{kg} \mathrm{BN}$. Measurements were taken in the nucleus of the solitary tract (NTS) at 3 levels; NTS1 $=$ obex, NTS2 $=-7.8 \mathrm{~mm}$ bregma, NTS3 $=-7.20 \mathrm{~mm}$ bregma, in the area postrema (AP, $7 \cdot 8 \mathrm{~mm}$ bregma) and in the paraventricular nucleus (PVN). *Significantly different from baseline condition $(0 \mathrm{nmol} / \mathrm{kg}, P<0 \cdot 05)$. ${ }^{\#}$ Significantly different from WT $(P<0 \cdot 05)$.

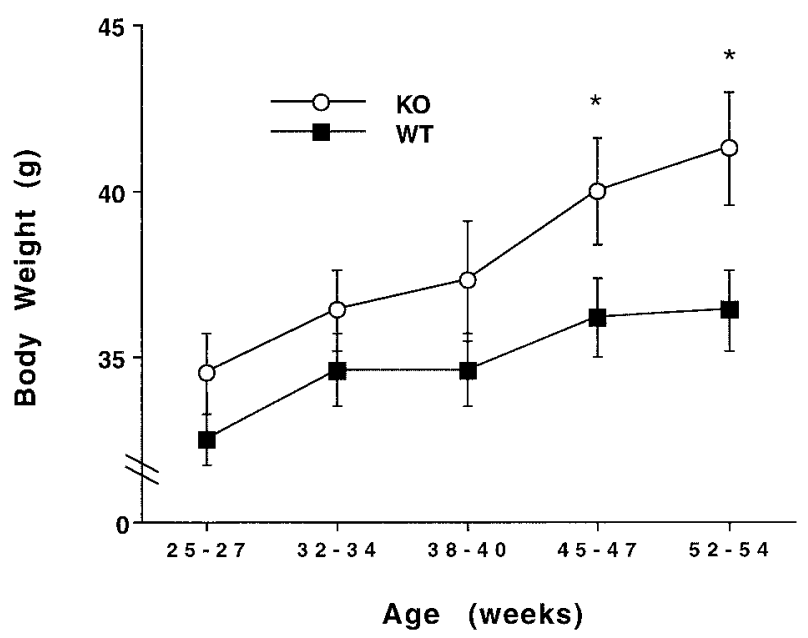

Figure 7 Measurements of body weight in GRP-R KO and WT littermates from age 25-54 weeks. Significant elevations in body weight were evident in GRP-R KO mice beginning at week 45 $\left({ }^{*} P<0 \cdot 05\right)$

mice is consistent with the conclusion that the feeding effects of BN-like peptides are mediated entirely by the GRP-R in mice.
Although a previous study using WT and NMB-R deficient mice (Ohki-Hamazaki et al. 1999) reported a similar conclusion, their study was based on examining feeding suppression using only a single threshold dose of $\mathrm{NMB}$ at a time when the majority of the feeding effects of NMB have diminished. Therefore to completely rule out the possibility that NMB does not contribute to feeding suppression in mice it was necessary to perform a complete dose-response analysis in both GRP-R KO and WT mice as well as evaluate earlier time points.

The inability of NMB to reduce food intake in mice is in contrast to our earlier report examining $\mathrm{BN}$ receptor contribution to feeding suppression in rats. Several experimental results have supported the view that NMB suppresses food intake independent of an interaction with GRP receptors in rats. For example, comparisons of the dose-effect curves for BN, GRP and NMB have indicated that, even at high dosages, NMB was less potent than either BN or GRP in reducing food intake. Furthermore, when a dose of NMB that was maximal for suppressing food intake was combined with a submaximal dose of GRP, the resulting suppression was greater than when either peptide was given alone (Ladenheim et al. 1996b). Finally, studies using a selective NMB-R antagonist demonstrated a complete blockade of feeding suppression 
induced by NMB but no effect on suppression induced by GRP (Ladenheim et al. 1994). These data suggest that species differences exist in the contribution of specific $\mathrm{BN}$ receptor subtypes to reduce food intake.

The analysis of c-Fos activation in response to $\mathrm{BN}$ administration in GRP-R KO and WT mice was in agreement with behavioral results. While $\mathrm{BN}$ resulted in increased c-Fos-positive cells in the AP, NTS and PVN in WT mice, only the PVN exhibited a significant increase in GRP-R KO mice. Previous studies have demonstrated that the caudal hindbrain, particularly the NTS, is a critical site for the suppression of food intake produced by peripherally administered BN-like peptides (Ladenheim \& Ritter 1993). Because BN activates both GRP-R and NMB-R, the inability of BN to elicit c-Fos activation in the NTS in GRP-R KO mice supports the interpretation that the GRP-R is the necessary receptor subtype for the feeding response in mice. Increased c-Fos activation in the PVN mice presumably resulted from activation of both GRP-R and NMB-R, because c-Fos induction still occurred in GRP-R KO mice after BN administration but was decreased compared with WT mice. Despite the lack of feeding effect of NMB these results show that NMB is still biologically active in mice. However, activation of this neuronal population must not contribute to feeding suppression since neither $\mathrm{BN}$ nor NMB suppressed feeding in GRP-R KO mice.

GRP-R KO mice also exhibited increased sensitivity to exogenous administration of CCK, in that a lower dose was required to produce a significant feeding suppression and the magnitude of the effect was greater than that of WT mice. It is possible that differences in sensitivity of GRP-R KO mice to other factors that control food intake may serve to compensate for loss of $\mathrm{BN}$ receptor activity and regulate food intake. However, our finding that individual meals were larger in GRP-R KO mice suggests that in normal feeding situations the compensation by other factors that could reduce meal size is incomplete.

At the time of behavioral testing there were no differences in body weight observed between GRP-R KO and WT mice. Yamada et al. (2000) previously reported that cumulative $24 \mathrm{~h}$ food intake was not different between GRP-R KO mice and their WT littermates, leading to the conclusion that lack of GRP-R did not affect food consumption. However, by conducting a more detailed analysis of meal patterns we revealed that differences in food consumption do exist between GRP-R KO and WT mice.

Previous studies have indicated that vena caval infusions of GRP given at the onset of the first nocturnal meal in spontaneously feeding rats reduce meal size with no significant effect on intermeal interval (Rushing et al. 1998). Therefore, our finding that GRP-R KO mice consume more at individual meals than WT mice is consistent with a deficit in a meal-related satiety signal. Furthermore, though not statistically significant due to a small sample size, the trend that less total meals were consumed to compensate for the increase in meal size suggests that there is a non-GRP-R-dependent compensatory mechanism that allows these mice to still regulate their overall energy intake.

Although no differences in body weight were evident during the behavioral testing period, the long-term comparison of body weight between the GRP-R KO and WT mice revealed a small $(12 \%)$, but significant, age-related increase in body weight beginning when the animals reached 45 weeks of age. Because we only conducted meal pattern analysis at one age, we do not know if GRP-R KO mice develop a less efficient means to compensate for larger meal size as they get older. As well, GRP-R KO mice have been shown to exhibit decreased glucagon-like peptide 1 secretion, impairment of insulin release and abnormal glucose tolerance that could eventually lead to metabolic disturbances and obesity (Persson et al. 2000). A determination of energy expenditure in GRP-R KO mice at different ages would be required to address this possibility.

In summary, the results of this study demonstrate that the satiety action of peripherally administered BN-like peptides is mediated by the GRP-R in mice. The increase in meal size seen in GRP-R KO mice suggests that this receptor subtype contributes to meal termination. GRP-R $\mathrm{KO}$ mice provide a useful approach for determining how BN receptor subtypes differentially affect behavioral and physiological responses to BN-like peptides.

\section{Acknowledgement}

This research was supported by NIH grant DK046448-09.

\section{References}

Anastasi A, Erspamer V \& Bucci M 1971 Isolation and structure of bombesin and alytesin, 2 analogous active peptides from the skin of the European amphibians Bombina and Alytes. Experientia 27 166-167.

Battey JF, Way JM, Corjay MH, Shapira H, Kusano K, Harkins R, Wu JM, Slattery T, Mann E \& Feldman RI 1991 Molecular cloning of the bombesin/gastrin-releasing peptide receptor from Swiss 3T3 cells. PNAS 88 395-399.

Fathi Z, Corjay MH, Shapira H, Wada E, Benya R, Jensen R, Viallet J, Sausville EA \& Battey JF 1993 BRS-3: a novel bombesin receptor subtype selectively expressed in testis and lung carcinoma cells. Journal of Biological Chemistry 268 5979-5984.

Franklin KBJ \& Paxinos G 1997 The Mouse Brain in Stereotaxic Coordinates. San Diego: Academic Press.

Gorbulev B, Akhundova A, Buchner H \& Fahrenholz F 1992 Molecular cloning of a new bombesin receptor subtype expressed in uterus during pregnancy. European Journal of Biochemistry 208 405-410.

Hampton LL, Ladenheim EE, Akeson M, Way JM, Weber HC, Sutliff VE, Jensen RT, Wine LJ, Arnheiter H \& Battey JF 1998 Loss of bombesin-induced feeding suppression in gastrin-releasing peptide receptor-deficient mice. PNAS 95 3188-3192. 
Kirkham TC, Walsh CA, Gibbs J, Smith GP, Leban J \& McDermed J 1994 A novel bombesin receptor antagonist selectively blocks the satiety action of peripherally administered bombesin. Pharmacology, Biochemistry and Behaviour 48 809-811.

Ladenheim EE \& Ritter RC 1993 Caudal hindbrain participation in suppression of feeding by central and peripheral bombesin. American Journal of Physiology 264 R1229-R1234.

Ladenheim EE, Jensen RT, Mantey SA \& Moran TH 1992 Distinct distributions of two bombesin receptor subtypes in the rat central nervous system. Brain Research 593 168-178.

Ladenheim EE, Taylor JE, Coy DH \& Moran TH 1994 Blockade of feeding inhibition by neuromedin B using a selective receptor antagonist. European Journal of Pharmacology 271 R7-R9.

Ladenheim EE, Taylor JE, Coy DH, Moore KA \& Moran TH 1996a Hindbrain GRP receptor blockade antagonizes feeding suppression by peripherally administered GRP. American Journal of Physiology 271 R180-R184.

Ladenheim EE, Wirth KE \& Moran TH $1996 b$ Receptor subtype mediation of feeding suppression by bombesin-like peptides. Pharmacology, Biochemistry and Behaviour 54 705-711.

Ladenheim EE, Moore KA, Salorio CF, Mantey SA, Taylor JT, Coy DH, Jensen RT \& Moran TH 1997 Characterization of bombesin binding sites in the rat stomach. European Journal of Pharmacology 319 245-251.

Lebacq-Verheyden AM, Trepel J, Sausville EA \& Battey JF 1990 Peptide growth factors and their receptors II. In Handbook of Experimental Pharmacology, pp 71-124. Eds M Sporn \& A Roberts. Berlin: Springer-Verlag.

Li BH \& Rowland NE 1996 Peripherally and centrally administered bombesin induce Fos-like immunoreactivity in different brain regions in rats. Regulatory Peptides 62 167-172.

Mantey SA, Weber HC, Sainz E, Akeson M, Ryan RR, Pradhan TK, Searles RP, Spindel E, Battey JF, Coy DH \& Jensen RT 1997 Discovery of a high affinity radioligand for the human orphan receptor, bombesin receptor subtype 3 , which demonstrates that it has unique pharmacology compared with other mammalian bombesin receptors. Journal of Biological Chemistry 272 2606226071.

Merali Z, McIntosh J \& Anisman H 1999 Role of bombesinrelated peptides in the control of food intake. Neuropeptides $\mathbf{3 3}$ 376-386.
Moran TH, Moody TW, Hostetler AM, Robinson PH, Goldrich M \& McHugh PR 1988 Distribution of bombesin binding sites in the rat gastrointestinal tract. Peptides 9 643-649.

Ohki-Hamazaki H, Sakai Y, Kamata K, Ogura H, Okuyama S, Watase K, Yamada K \& Wada K 1999 Functional properties of two bombesin-like peptide receptors revealed by the analysis of mice lacking neuromedin B receptor. Journal of Neuroscience 19 948-954.

Persson K, Gingerich RL, Nayak S, Wada K, Wada E \& Ahren B 2000 Reduced GLP-1 and insulin responses and glucose intolerance after gastric glucose in GRP receptor-deleted mice. American Journal of Physiology, Endocrinology and Metabolism 279 E956-E962.

Rushing PA, Henderson RP \& Gibbs J 1998 Prolongation of the post-prandial intermeal interval by gastrin-releasing peptide1-27 in spontaneously feeding rats. Peptides 19 175-177.

Spindel ER, Giladi E, Brehm P, Goodman RH \& Segerson TP 1990 Cloning and functional characterization of a complementary DNA encoding the murine fibroblast bombesin/gastrin-releasing peptide receptor. Molecular Endocrinology 4 1956-1963.

von Schrenk T, Heinz-Erian P, Moran TH, Mantey SA, Gardner JD \& Jensen RT 1989 Neuromedin B receptor in esophagus: evidence for subtypes of bombesin receptors. American Journal of Physiology 256 G747-G758.

Wada E, Way J, Lebacq-Verheyden AM \& Battey JF 1990 Neuromedin and gastrin-releasing peptide mRNAs are differentially distributed in the rat nervous system. Journal of Neuroscience $\mathbf{1 0}$ 2917-2930.

Wada E, Way J, Shapira H, Kusano K, Lebacq-Verheyden AM, Coy D, Jensen R \& Battey JF 1991 cDNA cloning, characterization, and brain region-specific expression of a neuromedin-B-preferring bombesin receptor. Neuron 6 421-430.

Wada E, Watase K, Ogura H, Yamano M, Inomata Y, Eguchi J, Yamamoto K, Sunday ME, Maeno H, Mikoshiba K, OhkiHamazaki H \& Wada K 1997 Generation and characterization of mice lacking gastrin-releasing peptide receptor. Biochemical and Biophysical Research Communications 239 28-33.

Yamada K, Wada E \& Wada K 2000 Bombesin-like peptides: studies on food intake and social behaviour with receptor knock-out mice. Annals of Medicine 32 519-529.

Received 8 April 2002

Accepted 19 April 2002 